\title{
Article \\ Time-Dependence of the Mechanical Behavior of Loess after Dry-Wet Cycles
}

\author{
Kai Liu ${ }^{1} \mathbb{D}$, Tianfeng Gu ${ }^{1, *}$, Xingang Wang ${ }^{1,2, * \mathbb{C}}$ and Jiading Wang ${ }^{1}$ \\ 1 State Key Laboratory of Continental Dynamics, Department of Geology, Northwest University, Xi'an 710069, \\ China; liukaii@stumail.nwu.edu.cn (K.L.); wangjddz@gmail.com (J.W.) \\ 2 State Key Laboratory of Geohazard Prevention and Geoenvironment Protection, Chengdu University of \\ Technology, Chengdu 610059, China \\ * Correspondence: gutf@nwu.edu.cn (T.G.); xgwang@nwu.edu.cn (X.W.)
}

Citation: Liu, K.; Gu, T.; Wang, X.; Wang, J. Time-Dependence of the Mechanical Behavior of Loess after Dry-Wet Cycles. Appl. Sci. 2022, 12, 1212. https://doi.org/10.3390/ app12031212

Academic Editors: Ricardo Castedo, Miguel Llorente Isidro and David Moncoulon

Received: 15 December 2021

Accepted: 23 January 2022

Published: 24 January 2022

Publisher's Note: MDPI stays neutral with regard to jurisdictional claims in published maps and institutional affiliations.

Copyright: (c) 2022 by the authors. Licensee MDPI, Basel, Switzerland. This article is an open access article distributed under the terms and conditions of the Creative Commons Attribution (CC BY) license (https:// creativecommons.org/licenses/by/ $4.0 /)$.

\begin{abstract}
The structure, time-dependent mechanical deformation, and strength characteristics of loess, which is loose and porous with well-developed vertical joints, are greatly affected by the dry-wet cycles, which are attributed to periodic artificial irrigation, rainfall, and water evaporation. To better understand the creep characteristics of loess under the effect of dry-wet cycles, $\mathrm{Q}_{2}$ loess samples obtained from the South Jingyang County, China, were subjected to different dry-wet cycles $(0,5,10,15,20)$ and sheared in triaxial creep tests. The experimental results revealed that: firstly, the maximum value of the deviatoric stress corresponding to creep failure gradually decreases with an increase in the dry-wet cycles. Secondly, the long-term strength of the loess after dry-wet cycles were obtained through the Isochronous Curve Method. It is found that the long-term strength and the number of dry-wet cycles showed an exponential decreasing relationship. In addition, the creep damage mechanism of loess due to dry-wet cycles is proposed. This study may provide the basis for understanding the mechanical behavior of the loess under the effect of dry-wet cycles, as well as guidelines for the prevention and prediction of loess landslide stability.
\end{abstract}

Keywords: loess; dry-wet cycles; triaxial creep test; creep behavior; strain-time; long-term strength

\section{Introduction}

Loess is a weakly cemented loose sediment with a special material composition, which is widely distributed in the Loess Plateau of China (Figure 1) [1,2]. Creep phenomenon is common in loess-covered areas, and the creep characteristics of loess pose an important impact on the landslide formation and the construction of engineering structures [3-5]. The creep properties of loess vary due to the change of the environment. For example, unsaturated loess soils are usually subjected to wetting because of the natural rainfall or artificial irrigation, and loess soils would then be subjected to a drying process, i.e., water evaporation, as rainfall or irrigation stops. Such a process could be called a drywet cycle [6,7] and leads to the following consequences: the loss of soluble salts in the loess [8-10], the deterioration of the mechanical properties of the loess [11,12], and the change of shear strength, deformation, and permeability of the loess [13-15]. Therefore, the creep deformation of the loess was aggravated, which will contribute to the formation of disasters such as landslides.

The influence of dry-wet cycles on the time-dependent behavior of rocks has been considered in some research [16-19], while in the last few years increasing attention has been paid to experimental research into the behavior of loess soils. It is acknowledged that the reduction in the shear strength of the loess due to the dry-wet cycles is obvious $[3,20,21]$. Malusis et al. [22] reported that the hydraulic conductivity of the soil gradually increases as the number of dry-wet cycles increases. Until now, extensive attempts have been made on the physical and mechanical properties of loess after dry-wet cycles by using the uniaxial tensile shear test [23], direct shear test [24,25], the uniaxial compressive test [26], 
conventional triaxial test $[7,27]$, the soil-water characteristic curve (SWCC) of loess [28], etc. For example, Yuan et al. [23] carried out an experimental study on the tensile strength of the intact loess samples under dry-wet cycles and concluded that the repeated dry-wet cycle destroys the original structure of the intact loess and causes its tensile strength to disappear. Furthermore, Mu et al. [24] investigated the shear characteristics of loess samples under dry-wet cycles through direct shear tests and pointed out that the shear strength of loess gradually decreased as the number of dry-wet cycles increase. By conducting experiments, $\mathrm{Li}$ et al. [26] reported that the unconfined compressive strength, elastic modulus, and cohesive force of the loess specimen decreased with an increase in the number of dry-wet cycles, while the vertical compressive strain and failure deformation increased. Hu et al. [27] conducted triaxial tests considering three influence factors such as dry density, dry-wet cycle amplitude, and the lower bound water content of dry-wet cycles and established a compacted loess deterioration model (CLDM). Wang et al. [29] explored the effect of the dry-wet cycle on the collapsible deformation characteristics of compacted loess, and the results revealed that the compressive strain at all levels of deviatoric stress of specimens with different initial density gradually increases with the increase of the number of dry-wet cycles. The higher the initial compaction degree, the more significant effect of the dry-wet cycle on the mechanical behavior of compacted loess.

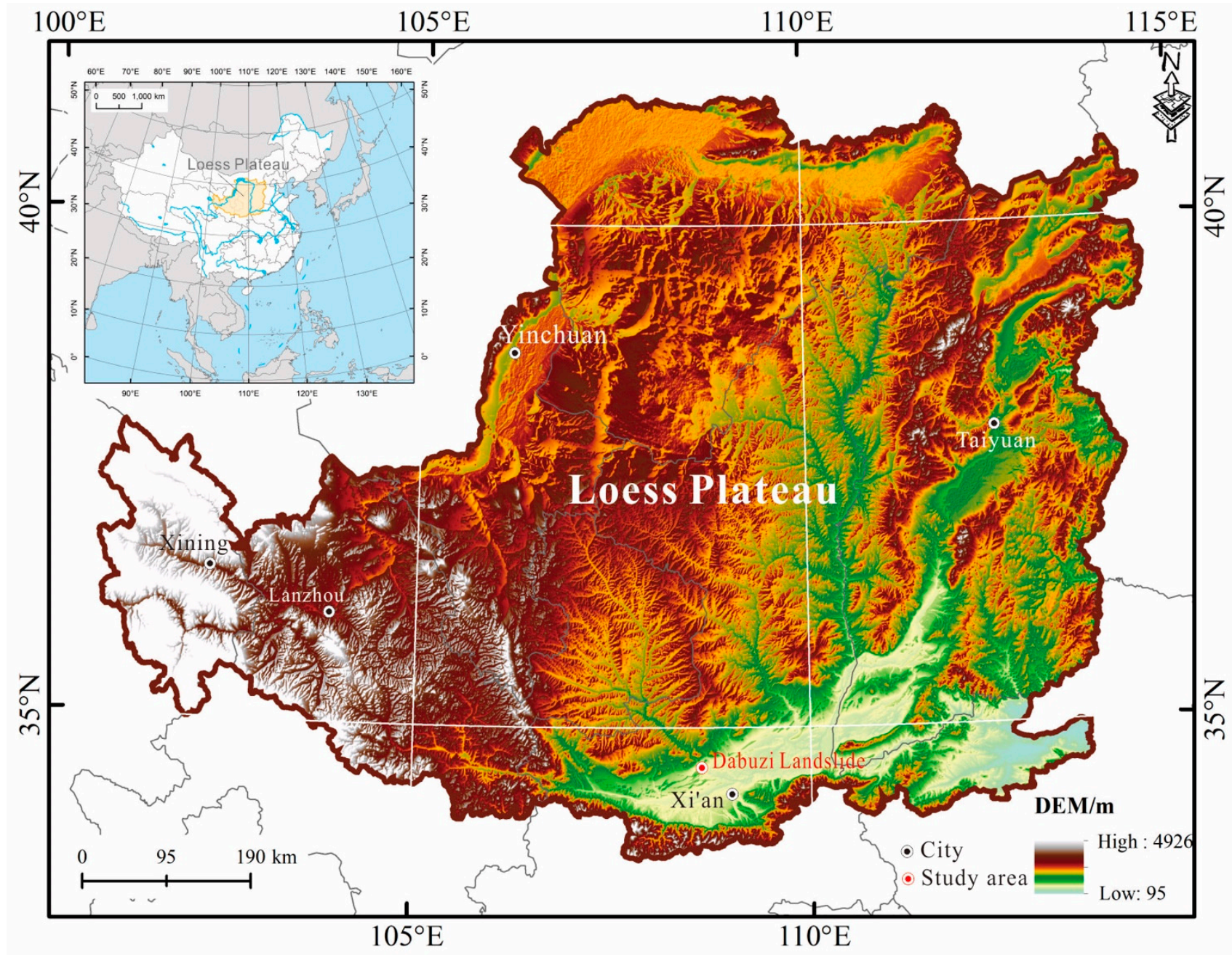

Figure 1. The study area.

The studies above have been focused on the variation in conventional mechanical properties such as shear strength, uniaxial tensile strength, uniaxial compressive strength, and triaxial shear strength of the loess after the dry-wet cycles. However, very little 
attention has been paid to the damaging effect of the dry-wet cycles on the creep properties of loess. Additionally, a few experimental results have shown that the creep strains of loess soils developed after dry-wet cycles are not negligible [30] and can reach a critical value, eventually triggering loess landslides. In this backdrop, typical loess samples obtained from South Jingyang, China, were used to conduct triaxial creep tests under different numbers of dry-wet cycles to gain full insight into the time-dependent characteristics of loess soils and the deterioration of the long-term strength caused by dry-wet cycles. Furthermore, the damage mechanism of the creep characteristics of loess due to the dry-wet cycles is explored. This study would be beneficial for understanding the time-dependence of mechanical behaviors of loess soils as well as the long-term stability of loess slopes.

\section{Triaxial Creep Tests}

\subsection{Sampling Site and Dry-Wet Cycle Process}

The loess samples used in test were collected from the back scalp of the Dabuzi landslide in Jingyang County, Shaanxi Province (Figure 1). The sampling site was about 20 $\mathrm{m}$ from the edge of the platform, and the collected samples were identified as Lishi loess (Q2) according to previous studies [31]. The loess in this area have suffered from different degrees of dry-wet cycles as a result of the long-term repeat rise and fall of the groundwater level due to the farmland irrigation (Figure 2a) [32]. Therefore, the mechanical properties of loess deteriorates, resulting in the occurrence of the Dabuzi landslide (Figure 2b). All loess samples were firstly sealed and kept in iron buckets. Then, samples were brought back to the laboratory and cut immediately to a cylindrical specimen with a diameter of $61.8 \mathrm{~mm}$ and height of $125 \mathrm{~mm}$. The procedures based on the ASTM standards were conducted to determine the index properties, namely Atterberg limits [33], specific gravity and density [34], and moisture content [35]. The basic physical index properties of loess are listed in Table 1.

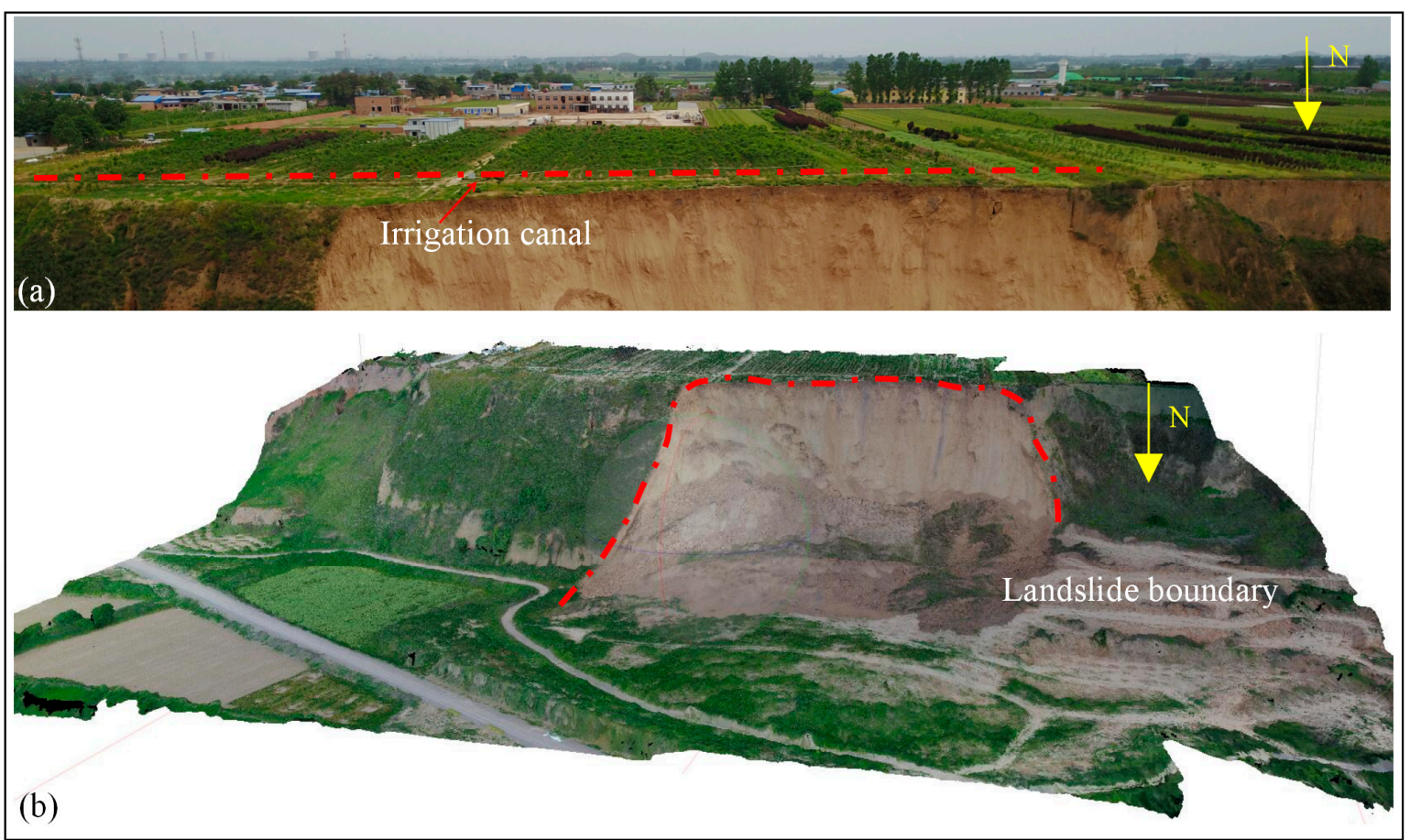

Figure 2. The sampling site. (a) Irrigation canal, (b) landslide boundary. 
Table 1. The physical index properties of loess.

\begin{tabular}{ccccc}
\hline Moisture Content $(\mathbf{\%})$ & Dry Density $\left(\mathrm{g} / \mathrm{cm}^{\mathbf{3}}\right)$ & Density $\left(\mathrm{g} / \mathbf{c m}^{\mathbf{3}}\right)$ & Specific Gravity & Void Ratio \\
\hline 16 & 1.503 & 1.858 & 2.711 & 0.768 \\
\hline
\end{tabular}

A two-step process for preparation of the sample was used with each dry-wet cycle. The first step is sample saturation, which is briefly described as follows. The specimens were saturated by the vacuum saturation method. Filter papers and porous stones were firstly placed on the top and bottom of the soil sample. Then, the soil sample was fixed in a saturator chamber, as shown in Figure 3a, and then the saturator chamber with the soil sample was tightened with screw nuts and placed in a vacuum container (Figure 3b). After that, the soil specimen was submerged in de-aired water inside a vacuum container for at least $24 \mathrm{~h}$ to achieve a degree of saturation greater than $97 \%$ [36,37]. The drying phase was followed by wetting. After saturation, the soil sample was taken out by loosening the screw nuts and removing the filter papers and porous stones. Then, the soil sample sealed by the saturator chamber was placed in a drying oven at about $105^{\circ} \mathrm{C}$ for $48 \mathrm{~h}$ to fully remove its water content $[38,39]$. Next, the soil sample was taken out and cooled down. This process, consisting of saturation and drying phases, is called one dry-wet cycle in this study. After the last dry-wet cycle, the corresponding water required to obtain the target water content was dripped on the top surface of the soil sample, and then the soil sample was wrapped with a plastic wrap and placed in a humidifier for $48 \mathrm{~h}$ to obtain a homogeneous sample in room temperature [40,41]. In this study, samples with different dry-wet cycles $(0,5,10,15$, and 20) were prepared and the sample after 10 dry-wet cycles was shown in Figure 3c.

(a)

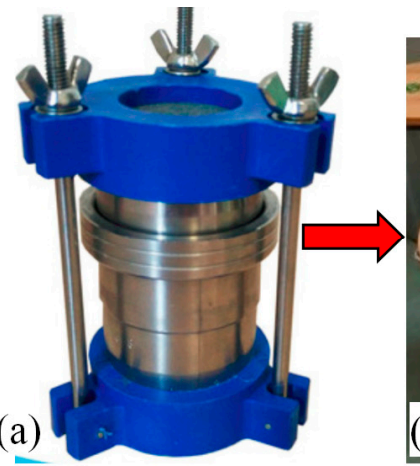

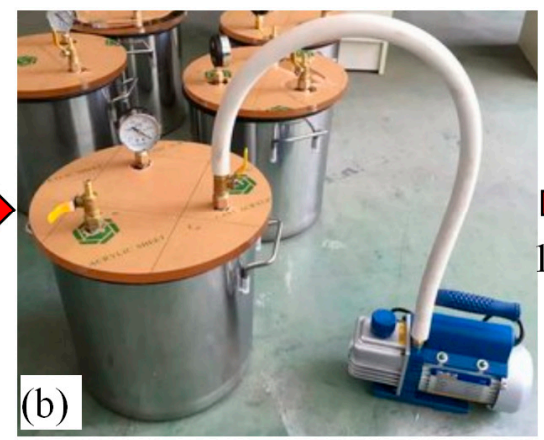

(c)

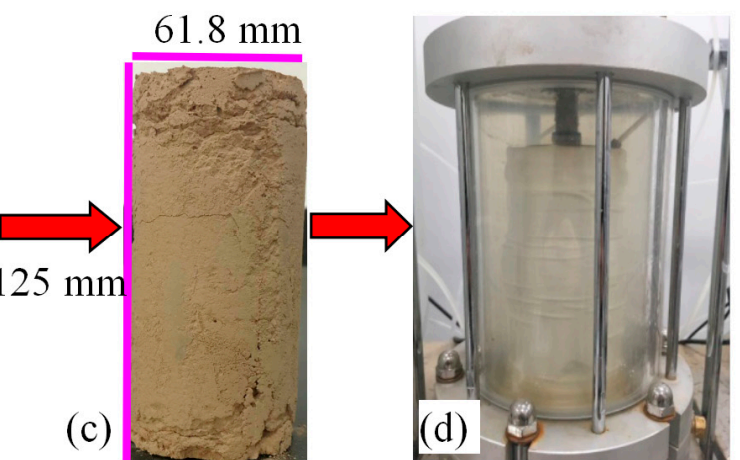

Figure 3. Specimen with the dry-wet cycles. (a) Frame saturator chamber, (b) vacuum container, (c) specimen after dry-wet cycles, (d) triaxial chamber.

\subsection{Testing Apparatus}

The FSR-20 triaxial creep apparatus for the testing cylinder of soil samples with a height of $125 \mathrm{~mm}$ and diameter of $61.8 \mathrm{~mm}$ in the State Key Laboratory of Continental Dynamics in China (see Figures 3c and 4) was utilized in this study. As shown in Figure 4, the apparatus consists of several parts, such as an axial loading system, pore water pressure controlling system, confining pressure controlling system, matric suction controlling system, data measurement, and a collect system. By using a pneumatic servo control system, the apparatus is capable of providing not only constant shear stress but also constant air pressure for a long time with high accuracy [3,42]. Creep tests can be carried out for confining pressure up to $1 \mathrm{MPa}$, pore water pressure up to $500 \mathrm{kPa}$, axial load up to $2 \mathrm{MPa}$, and pore gas pressure up to $500 \mathrm{kPa}$. The tests may be run either undrained or consolidated undrained with or without pore water pressure measurement, or drained condition. In this study, drained creep tests were conducted on loess samples. 


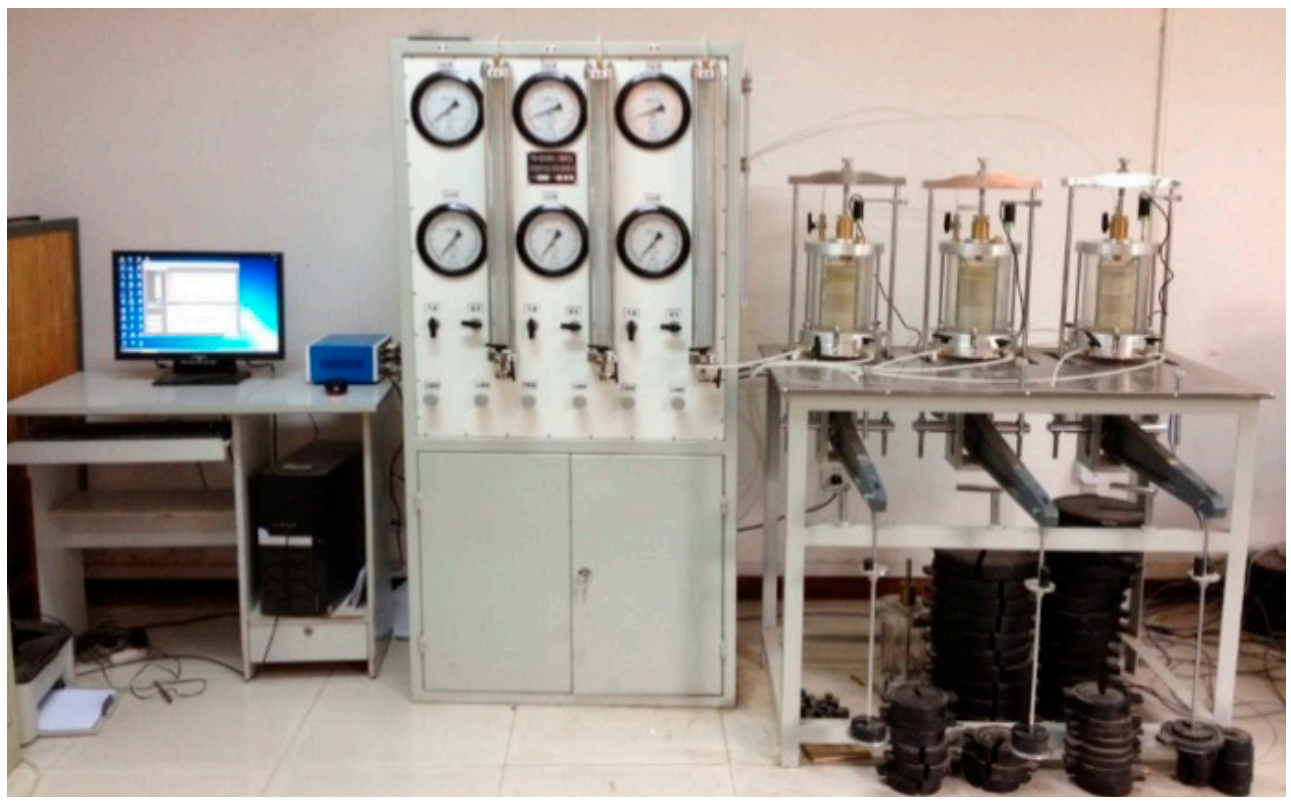

Figure 4. FSR-20 triaxial creep apparatus.

\subsection{Testing Scheme}

According to the basic physical index properties listed in Table 1, samples with a moisture content of $16 \%$ were tested by using multi-level loading method $[4,43]$. Considering the density $\left(\rho=1858 \mathrm{~kg} / \mathrm{m}^{3}\right)$ and the thickness $(20 \mathrm{~m})$ of the overlying loess, the confining pressure of $200 \mathrm{kPa}$ was chosen for the triaxial creep test. The multi-level loading method used in this study is described as follows: the first level of deviatoric stress was applied to the specimen until the stability was attained when the deformation of the specimen was less than $0.01 \mathrm{~mm}$ in $24 \mathrm{~h}$. To find an optimum time during which the deformation of the specimen was less than $0.01 \mathrm{~mm}$, a series of preliminary tests were conducted, where $24 \mathrm{~h}$, $36 \mathrm{~h}$, and $48 \mathrm{~h}$ were used for specimens with the same testing conditions. The creep shear test results show that for the cases of $24 \mathrm{~h}, 36 \mathrm{~h}$, and $48 \mathrm{~h}$, the strength and strain-time curves of loess have no obvious difference, indicating that $24 \mathrm{~h}$ is enough for obtaining the stability state of the loess. Therefore, $24 \mathrm{~h}$ was selected here from the point of view of time saving. Then, the second level of deviatoric stress was applied to the specimen until the stability state was achieved. The specimen was subjected to shearing until creep failure occurred at some level of deviatoric stress. In this study, the failure occurred in the specimen when the strain of specimen reached $20 \%$ following the previous study concluded by Xie et al. [44]. The samples after different dry-wet cycles were subjected to consolidation and shearing in the conventional triaxial compression test to calculate the instantaneous failure strength. Then, the loading scheme of the triaxial creep test (Table 2) was determined according to the instantaneous failure strength.

Table 2. Loading scheme of the triaxial creep test.

\begin{tabular}{cc}
\hline The Number of Dry-Wet Cycles & Deviatoric Stress/kPa \\
\hline 0 & $25,50,62.5,75,87.5,100,150,250,350$ \\
5 & $50,100,150,200,250,300$ \\
10 & $50,125,200,250,300$ \\
15 & $50,100,175,250$ \\
20 & $50,100,175,250$ \\
\hline
\end{tabular}




\section{Test Results}

Based on the experimental data collected, the typical creep strain curves for loess with a different number of dry-wet cycles is plotted in Figures 5-9. After that, according to Boltzmann's linear superposition principle [45,46], the creep curves corresponding to each level of deviatoric stress was obtained by using "the coordinate translation method" [47,48]. Figures 5-9 show the whole process curve of creep for loess and creep curves of loess with a different number of dry-wet cycles. In Figures 5-9, $q$ represents the deviatoric stress, $\varepsilon$ is strain, $w$ is the moisture content, and $t$ is time.
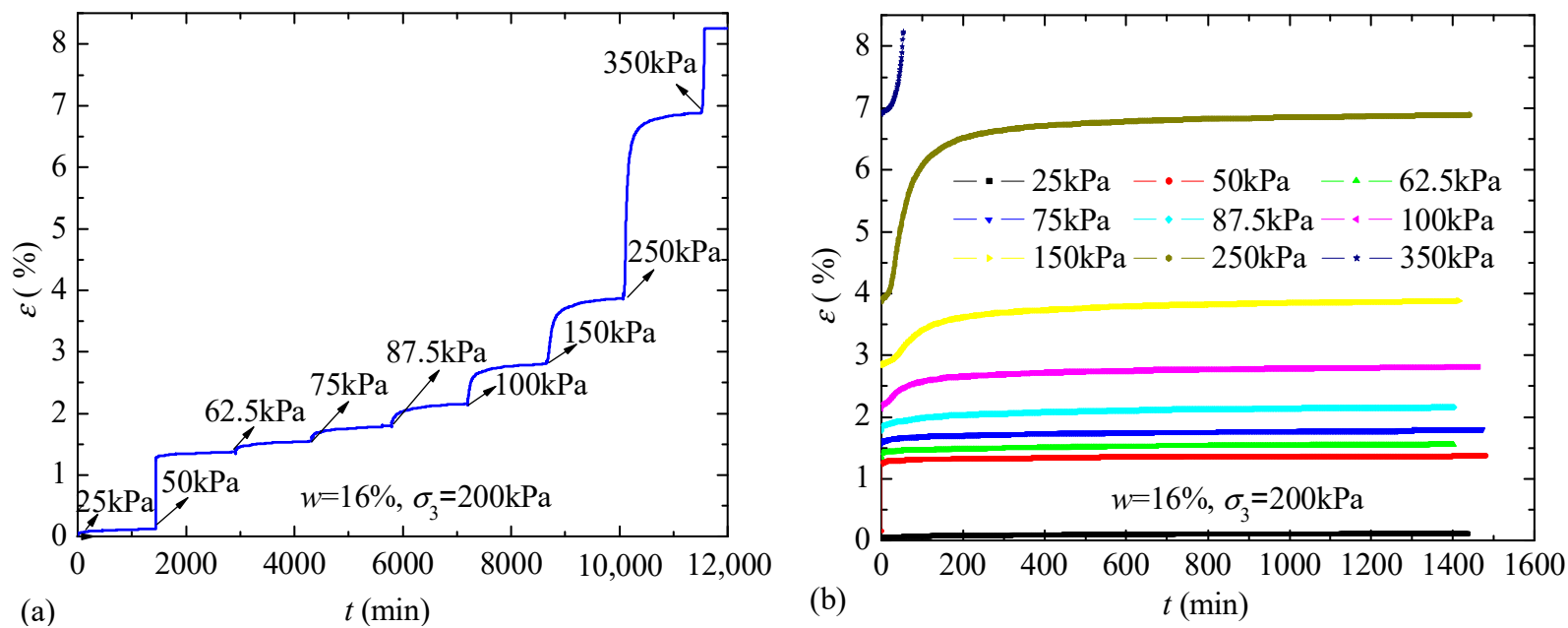

Figure 5. (a) The whole process curve of creep for loess without dry-wet cycles, (b) creep curves of the loess without dry-wet cycles.
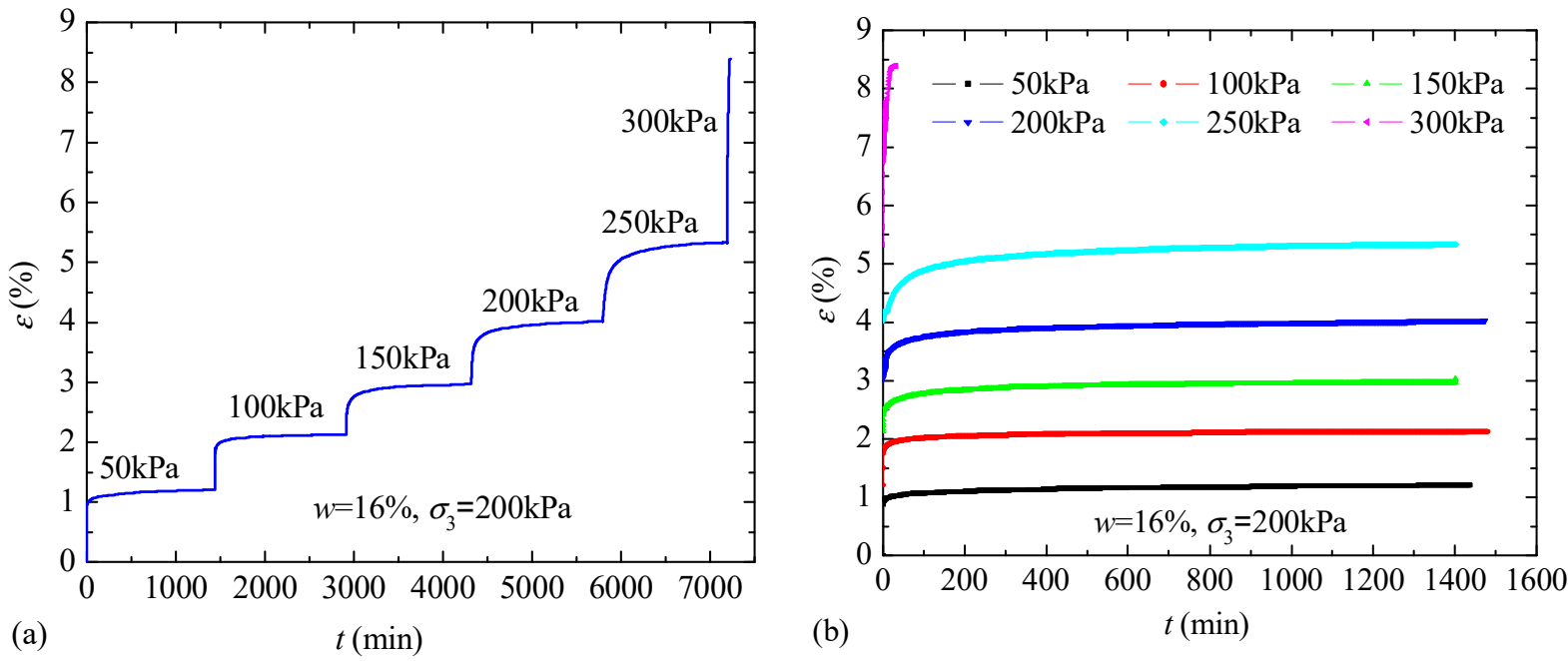

Figure 6. (a) The whole process curve of creep for loess with 5 dry-wet cycles, (b) creep curves of loess with 5 dry-wet cycles. 

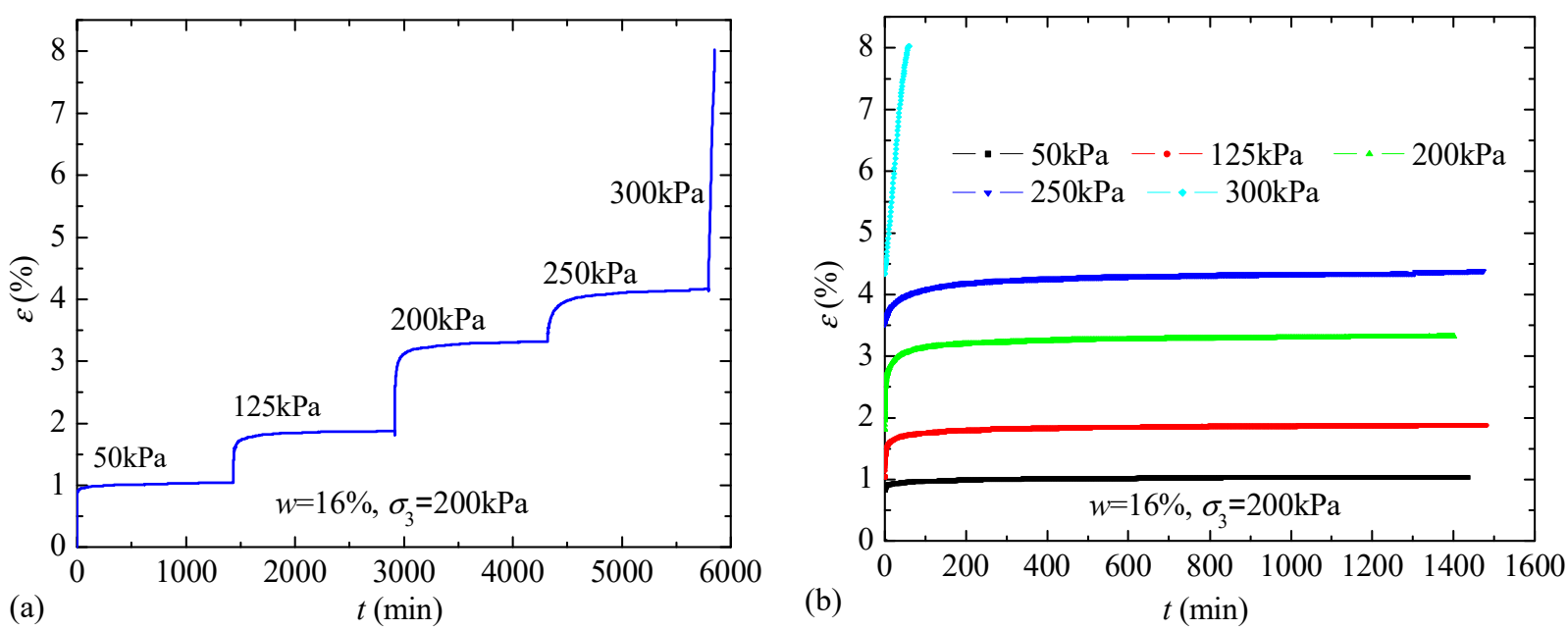

Figure 7. (a) The whole process curve of creep for loess with 10 dry-wet cycles, (b) creep curves of loess with 10 dry-wet cycles.
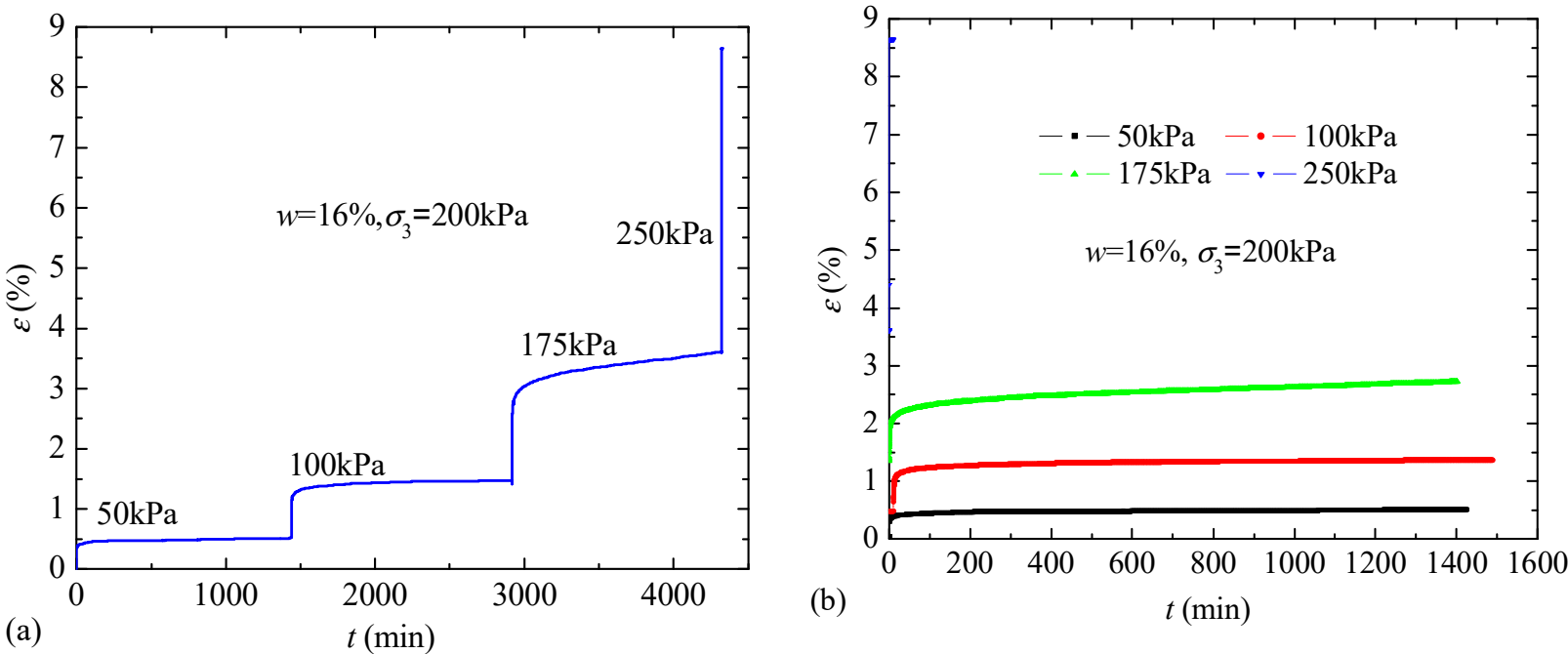

Figure 8. (a) The whole process curve of creep for loess with 15 dry-wet cycles, (b) creep curves of loess with 15 dry-wet cycles.

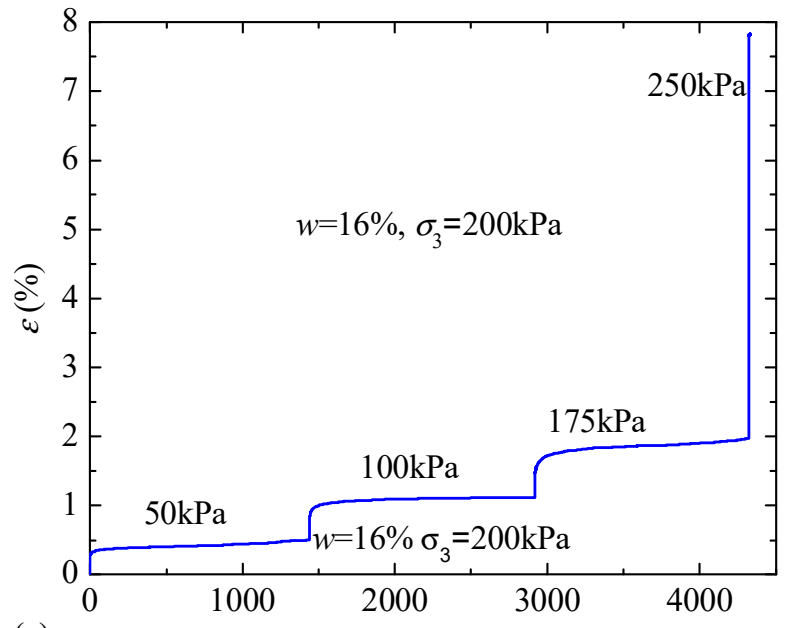

(a)

$t(\min )$

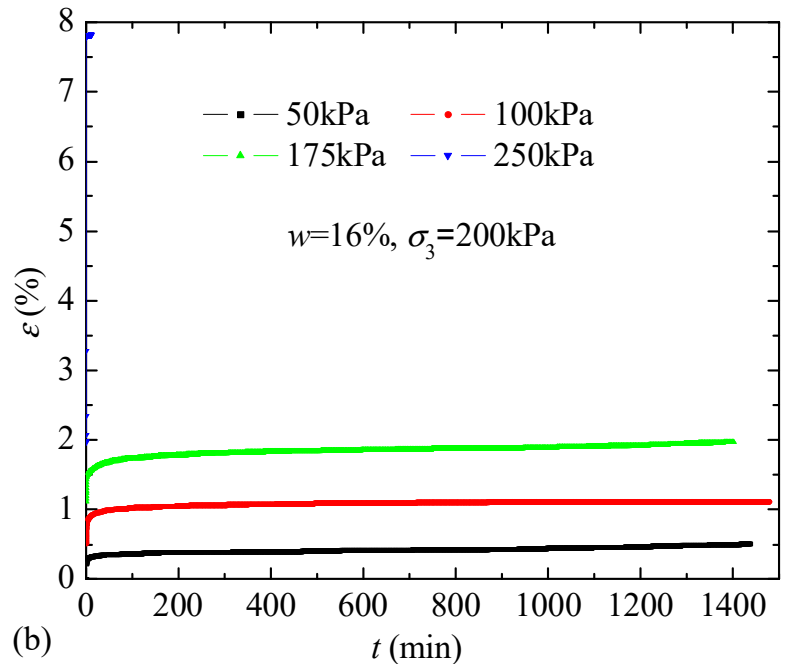

Figure 9. (a) The whole process curve of creep for loess with 20 dry-wet cycles, (b) creep curves of loess with 20 dry-wet cycles. 
It can be observed from Figures 5-9 that the characteristics of the whole process curve of creep for loess and creep curves are as follows: (i) The specimen with different drywet cycles underwent three typical creep stages, namely the decelerating creep stage, the steady state stage, and accelerate creep stage. With the same number of dry-wet cycles, the creep curve tends to be flat with an increase of time when a small load is applied, that is, the steady state stage. However, with a higher loading, the creep curve of the stable phase increases linearly with time. (ii) The slope of the curve corresponding to the steady state stage increases with an increase of loading. However, sudden failures could be observed within the loess specimen once the load exceeds a certain value. For example, when the deviator stress of the sample with 20 dry-wet cycles increased to 250 $\mathrm{kPa}$, the deformation dramatically increases. (iii) With the increase of the number of drywet cycles, the maximum value of the deviatoric stress corresponding to the creep failure gradually decreases, indicating that the creep strength of the sample is deteriorated by the dry-wet cycles.

\section{Discussion}

\subsection{The Long-Term Strength of Loess Samples with Different Dry-Wet Cycles}

The long-term strength of rock and soil is an important parameter for assessing the stability of landslides $[49,50]$. At present, the main methods to obtain long-term strength through creep test curves include the isochronous curve method [3,51], which uses the creep test curve and the Boltzmann superposition principle [52] and states that the stress response of a system to a time dependent shearing deformation may be written as the sum of responses to a sequence of step strain perturbations in the past [53], to obtain the stress-strain isochronous curves corresponding to the different deviatoric stress at the same time [54]. Figure 10a-e show the isochronous curves corresponding to the creep curves of the samples after five kinds of dry-wet cycles $(n=0,5,10,15,20)$. Based on the isochronous curves, the long-term strength $\left(q_{\mathrm{L}}\right)$ was obtained.

The experimental data listed in Table 3 was plotted in Figure 11. One can observe that there is a clear correlation between the long-term strength and the number of dry-wet cycles. The overall relationship between the long-term strength of loess and the number of dry-wet cycles can be described by the following equation:

$$
q_{L}=123.50 \mathrm{e}^{(-n / 9.98)}+127.33, n \leq 20,
$$

where $q_{L}$ is the long-term strength measured in $\mathrm{kPa}$ and $n$ is the number of the drywet cycles.

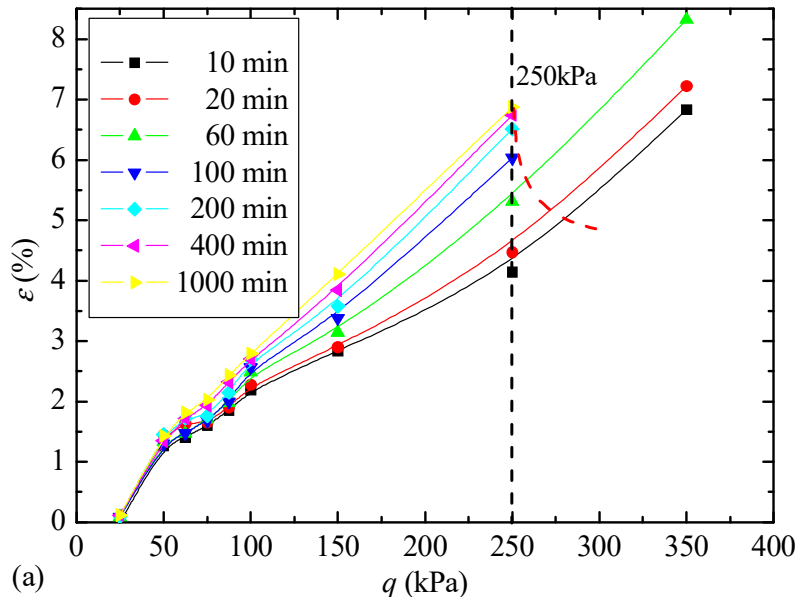

Figure 10. Cont.

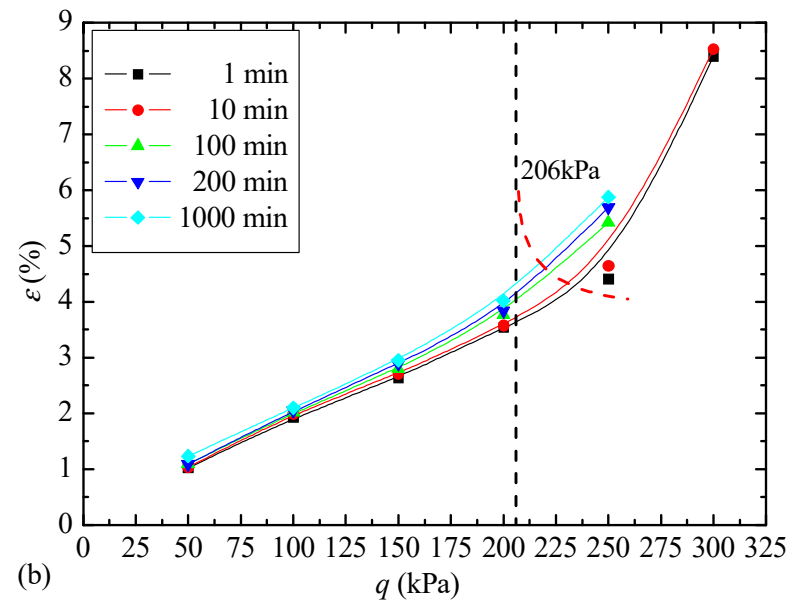

(b)

$q(\mathrm{kPa})$ 

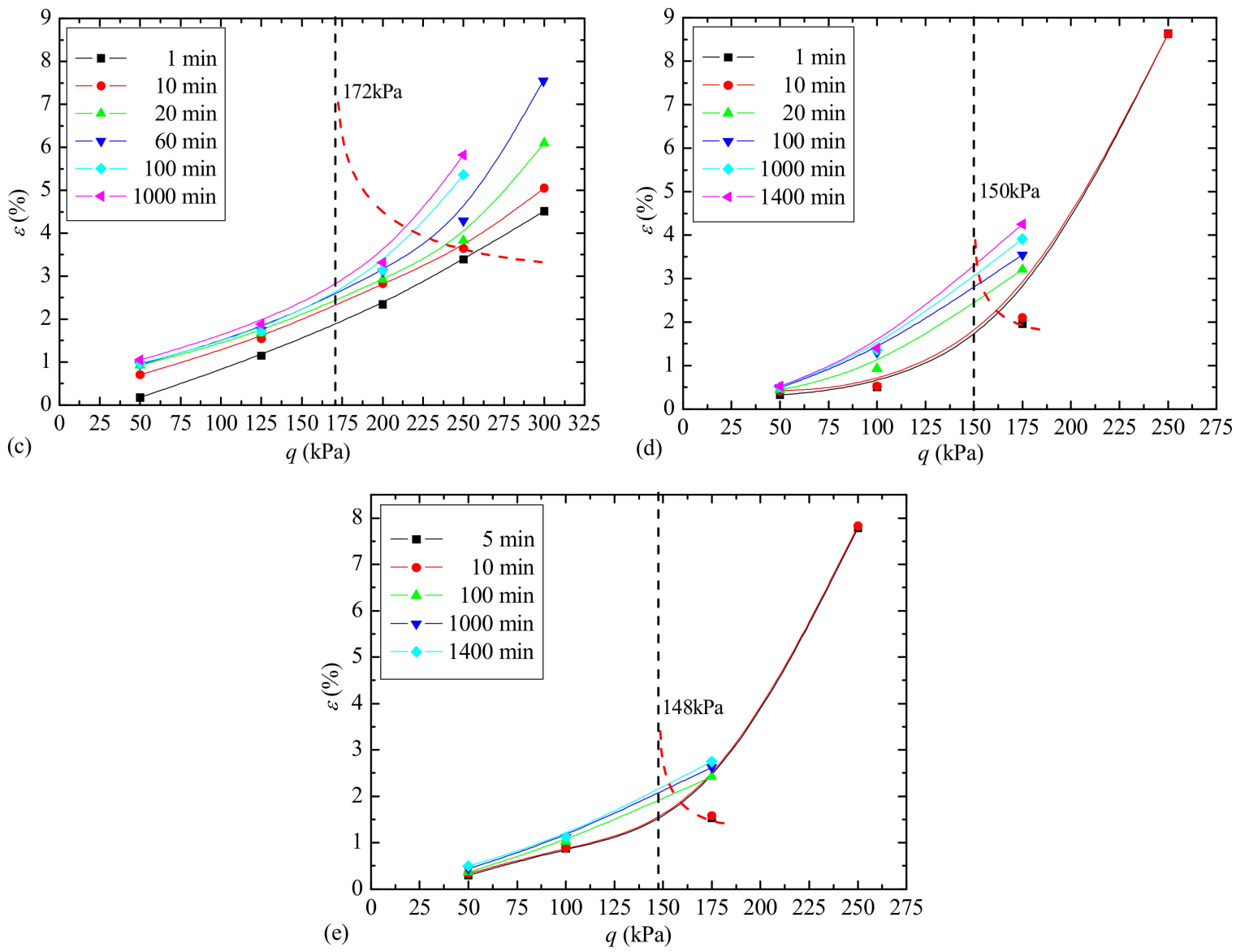

Figure 10. Creep isochronous curve after different dry-wet cycles. (a) $n=0,(\mathbf{b}) n=5,(\mathbf{c}) n=10$, (d) $n=15,(\mathbf{e}) n=20$.

Table 3. Long-term strength after different dry-wet cycles (qL).

\begin{tabular}{cccccc}
\hline $\boldsymbol{n}$ & $\mathbf{0}$ & $\mathbf{5}$ & $\mathbf{1 0}$ & $\mathbf{1 5}$ & $\mathbf{2 0}$ \\
\hline$q_{\mathrm{L}}$ & 250 & 206 & 172 & 150 & 148 \\
\hline
\end{tabular}

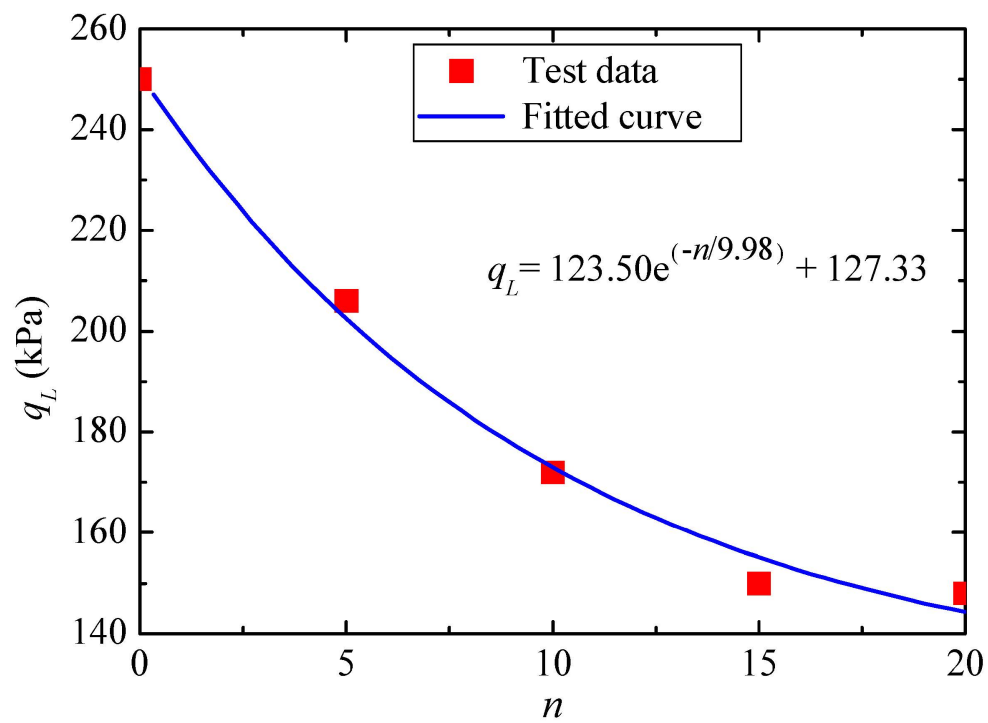

Figure 11. The fitting curve of the long-term strength after different dry-wet cycles. 
It is clear that the long-term strength of loess decreases when increasing the dry-wet cycles. However, the reducing magnitude of long-term strength gradually decreases with the increase of the number of dry-wet cycles, until it reaches a constant value. That is to say, the long-term strength of the loess and the number of dry-wet cycles $(n \leq 20)$ shows an exponential decreasing relationship (see Equation (1)).

\subsection{Creep Damage Mechanism of Loess Samples Due to the Dry-Wet Cycles}

The creep damage mechanism of the loess samples due to the dry-wet cycles was explained from the perspective of macro pictures of the loess samples after creep failure and the change of long-term strength with dry-wet cycles. Figure 12 shows loess samples after experiencing creep failure. One can observe that the obvious failure surface did not appear in the specimen, whereas the bending and bulging occurred on the side of the specimen. Furthermore, as the number of dry-wet cycles increases, the phenomenon of bending and bulging of the specimen becomes more noticeable. Such a phenomenon can be explained as follows: under the effect of a dry-wet cycle, the microstructure of loess is destroyed due to the repeated migration and loss of soluble salts between soil particles in the loess sample $[8,10]$. Moreover, the dry-wet cycles also promote the development and expansion of joint fractures in the loess sample [7], resulting in the worsening of the creep mechanical properties (see Table 3 and Figure 11). As the number of dry-wet cycles further increased, the dissolved salts in the loess sample gradually dissolved in water, which results in the coarse particles being further dispersed and disintegrated and the total pore volume of the sample being increased [25]. Therefore, the creep curves of the loess specimen show a strain-softening pattern, and the bending or lateral swelling occurred in the specimen (see Figure 12, $n=5$ and $n=10$ ). When the number of dry-wet cycles reaches a certain value, structural stability (micro- and macro-structure stability) within the loess soils was achieved. Consequently, the long-term strength of loess samples tends to be stable (see Figure 10, $n=15$ and $n=20$ ), causing the creep mechanical properties to be consistent with each other.

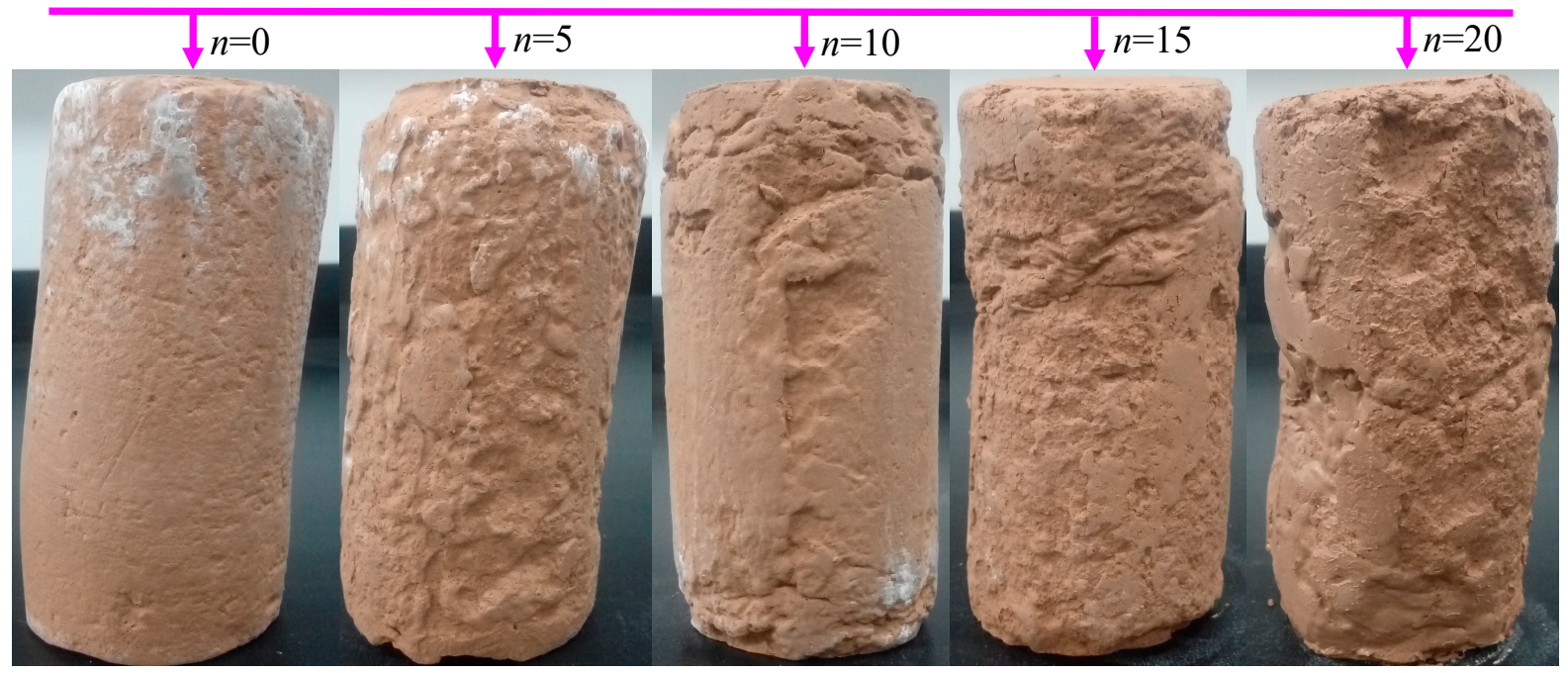

Figure 12. Specimen after creep failure.

\subsection{Limitations of the Experimental Test in This Study}

Concerning the influence of dry-wet cycles, the experimental results herein can be used for the determination of numerical simulation parameters and for better evaluating the longterm stability of loess slopes. Therefore, the study would be beneficial to understanding the time-dependence of the mechanical behaviors of loess soils as well as the long-term stability of loess slopes, which provide the basis for understanding the mechanical behavior of the loess under the effect of dry-wet cycles, as well as guidelines for the prevention and 
prediction of loess landslide stability. However, there are some potential limitations in this study that could be addressed in future research. First, the loess samples were sheared under a saturated condition with a maximum value of 20 dry-wet cycles, whereas the triaxial creep tests were not conducted on unsaturated loess samples with a wide range of dry-wet cycles. Therefore, the conclusions and theoretical formulas obtained in this study have certain restrictions. Secondly, the water used in this study is distilled water, which is unrealistic due to the fact that the water in the filed contains many mixtures due to solute transport and other chemical effects [10,55-57]. Finally, the influence of dry-wet cycle on loess in the field is very complicated due to the influence of rainfall, irrigation water, evaporation, and other factors [8,9,11,12], which could not be simply simulated by dry-wet cycles. On the other side, it is difficult to estimate the actual number of dry-wet cycles that the loess experienced in the field. Thus, there are some difficulties in applying the experimental results in this study to engineering practice. All limitations above would be considered in future research.

\section{Conclusions}

To assist in the understanding of the time-dependent behaviors and the long-term stability of loess slopes after dry-wet cycles, the mechanical properties of intact loess samples were investigated through triaxial creep tests. The following conclusions can be drawn according to the obtained experimental results:

(i) With the same number of dry-wet cycles, the strain-time curve of the loess samples shows a similar trend, where the strain eventually reaches a certain value with an increase of time when a small load is applied, whereas the creep curve of the stable phase increases linearly with time when the loess specimen is subjected to a higher loading. As the number of dry-wet cycles increases, the maximum value of the deviatoric stress corresponding to the creep failure gradually decreases, indicating that the deterioration of triaxial compressive strength is attributed to the dry-wet cycles.

(ii) The long-term strength of loess samples with different dry-wet cycles was obtained by using the Isochronous Curve Method, and the long-term strength of loess samples and the number of dry-wet cycles showed an exponential decreasing relationship.

(iii) The creep damage mechanism of loess samples due to dry-wet cycles can be explained as follows: the dry-wet cycle causes repeated migration and loss of soluble salts between soil particles in the loess sample, which results in damage of the sample's microstructure. Consequently, the development and expansion of joint fractures within the loess samples were also aggravated. The combined effects of microstructural damage and expansion of joint fractures causes a greater deterioration in the creep properties of loess soils.

Author Contributions: Conceptualization, X.W. and T.G.; methodology, K.L.; software, X.W. and K.L.; writing-original draft preparation, K.L.; writing-review and editing, X.W. and T.G.; visualization, X.W.; supervision, J.W.; funding acquisition, X.W. All authors have read and agreed to the published version of the manuscript.

Funding: This research was supported by the National Natural Science Foundation of China (No. 41902268) and the Opening Fund of State Key Laboratory of Geohazard Prevention and Geoenvironment Protection (Chengdu University of Technology) (No. SKLGP2020K016).

Institutional Review Board Statement: Not applicable.

Informed Consent Statement: Not applicable.

Data Availability Statement: Not applicable.

Acknowledgments: We thanks the editors, and the two anonymous reviewers for their constructive comments, which has helped us improve the quality of the manuscript.

Conflicts of Interest: The authors declare no conflict of interest. 


\section{References}

1. Derbyshire, E.; Dijkstra, T.; Smalley, I.; Li, Y. Failure mechanisms in loess and the effects of moisture content changes on remoulded strength. Quat. Int. 1994, 24, 5-15. [CrossRef]

2. Lian, B.; Peng, J.; Zhan, H.; Huang, Q.; Wang, X.; Sheng, H. Formation mechanism analysis of irrigation-induced retrogressive loess Landslides. Catena 2020, 195, 104441. [CrossRef]

3. Wang, X.; Wang, J.; Zhan, H.; Li, P.; Qiu, H.; Hu, S. Moisture content effect on the creep behavior of loess for the catastrophic Baqiao landslide. Catena 2020, 187, 104371. [CrossRef]

4. Lian, B.; Wang, X.; Peng, J.; Huang, Q. Shear rate effect on the residual strength characteristics of saturated loess in naturally drained ring shear tests. Nat. Hazards Earth Syst. Sci. 2020, 20, 2843-2856. [CrossRef]

5. Yates, K.; Fenton, C.H.; Bell, D.H. A review of the geotechnical characteristics of loess and loess-derived soils from Canterbury, South Island, New Zealand. Eng. Geol. 2018, 236, 11-21. [CrossRef]

6. Pan, P.; Shang, Y.-Q.; Lü, Q.; Yu, Y. Periodic recurrence and scale-expansion mechanism of loess landslides caused by groundwater seepage and erosion. Bull. Int. Assoc. Eng. Geol. 2017, 78, 1143-1155. [CrossRef]

7. Xu, J.; Li, Y.; Wang, S.; Wang, Q.; Ding, J. Shear strength and mesoscopic character of undisturbed loess with sodium sulfate after dry-wet cycling. Bull. Eng. Geol. Environ. 2020, 79, 1523-1541. [CrossRef]

8. Fan, X.; Xu, Q.; Scaringi, G.; Li, S.; Peng, D. A chemo-mechanical insight into the failure mechanism of frequently occurred landslides in the Loess Plateau, Gansu Province, China. Eng. Geol. 2017, 228, 337-345. [CrossRef]

9. Zhang, F.; Wang, G. Effect of irrigation-induced densification on the post-failure behavior of loess flowslides occurring on the Hei-fangtai area, Gansu, China. Eng. Geol. 2017, 236, 111-118. [CrossRef]

10. Zhang, F.; Wang, G.; Kamai, T.; Chen, W.; Zhang, D.; Yang, J. Undrained shear behavior of loess saturated with different concen-trations of sodium chloride solution. Eng. Geol. 2013, 155, 69-79. [CrossRef]

11. Wen, B.-P.; Yan, Y.-J. Influence of structure on shear characteristics of the unsaturated loess in Lanzhou, China. Eng. Geol. 2014, 168, 46-58. [CrossRef]

12. Xu, L.; Coop, M.R. Influence of structure on the behavior of a saturated clayey loess. Can. Geotech. J. 2016, 53, 1026-1037. [CrossRef]

13. Billard, A.; Muxart, T.; Derbyshire, E.; Wang, J.T.; Dijkstra, T. Landsliding and land use in the loess of Gansu Province, China Supplementband 1993, 87, 117-131.

14. Carey, J.M.; McSaveney, M.J.; Petley, D.N. Dynamic liquefaction of shear zones in intact loess during simulated earthquake loading. Landslides 2016, 14, 789-804. [CrossRef]

15. Sorbino, G.; Nicotera, M.V. Unsaturated soil mechanics in rainfall-induced flow landslides. Eng. Geol. 2012, 165, 105-132. [CrossRef]

16. Liu, X.; Jin, M.; Li, D.; Zhang, L. Strength deterioration of a Shaly sandstone under dry-wet cycles: A case study from the Three Gorges Reservoir in China. Bull. Eng. Geol. Environ. 2017, 77, 1607-1621. [CrossRef]

17. Sawatsubashi, M.; Kiyota, T.; Katagiri, T. Effect of initial water content and shear stress on immersion-induced creep deformation and strength characteristics of gravelly mudstone. Soils Found. 2021, 61, 1223-1234. [CrossRef]

18. Wang, X.-G.; Lian, B.-Q.; Wang, J.-D.; Feng, W.-K.; Gu, T.-F. Creep damage properties of sandstone under dry-wet cycles. J. Mt. Sci. 2020, 17, 3112-3122. [CrossRef]

19. Zhang, F.; Jiang, A.; Yang, X. Shear creep experiments and modeling of granite under dry-wet cycling. Bull. Eng. Geol. Environ. 2021, 80, 5897-5908. [CrossRef]

20. Khan, M.A.; Hossain, M.S.; Samir, S.; Aramoon, A. Impact of Wet-Dry Cycles on the Shear Strength of High Plastic Clay Based on Direct Shear Testing. Geotech. Front. 2017, 2017, 615-622. [CrossRef]

21. Tang, C.; Shi, B.; Liu, C.; Zhao, L.; Wang, B. Influencing factors of geometrical structure of surface shrinkage cracks in clayey soils. Eng. Geol. 2008, 101, 204-217. [CrossRef]

22. Malusis, M.A.; Yeom, S.; Evans, J.C. Hydraulic conductivity of model soil-bentonite backfills subjected to wet-dry cycling. Can. Geotech. J. 2011, 48, 1198-1211. [CrossRef]

23. Yuan, Z.; Tang, C.; Yang, P.; Shu, A.; Yang, L. Experimental studies of compressive strength of undisturbed loess in drying-wetting cycle. J. Eng. Geol. 2018, 26, 155-161. (In Chinese)

24. Mu, H.; Deng, Y.; Rongjian, L.I. Experimental study on strength characteristics of loess at ground fissures in xi'an under action of dry and wet cycle. J. Eng. Geol. 2018, 26, 1132-1137. (In Chinese)

25. Yan, C.; Zhang, Z.; Jing, Y. Characteristics of strength and pore distribution of lime-flyash loess under freeze-thaw cycles and dry-wet cycles. Arab. J. Geosci. 2017, 10, 544. [CrossRef]

26. Li, G.; Wang, F.; Ma, W.; Fortier, R.; Mu, Y.; Mao, Y.; Hou, X. Variations in strength and deformation of compacted loess exposed to wetting-drying and freeze-thaw cycles. Cold Reg. Sci. Technol. 2018, 151, 159-167. [CrossRef]

27. Hu, C.; Yuan, Y.; Wang, X.; Mei, Y.; Liu, Z. Experimental study on strength deterioration model of compacted loess under wet-ting-drying cycles. Chin. J. Rock Mech. Eng. 2018, 37, 2804-2818. (In Chinese)

28. Zhao, T.; Wang, J. Soil-water characteristic curve for unsaturated loess soil considering density and wetting-drying cycle effects. J. Cent. South Univ. Sci. Technol. 2012, 43, 2445-2453.

29. Wang, F.; Li, G.; Mu, Y.; Zhang, P.; Fan, S. Experimental study of deformation characteristics of compacted loess subjected to dry-ing-wetting cycle. Rock Soil Mech. 2016, 37, 2306-2312. 
30. Xu, J.; Li, Y.; Ren, C.; Lan, W. Damage of saline intact loess after dry-wet and its interpretation based on SEM and NMR. Soils Found. 2020, 60, 911-928. [CrossRef]

31. Wei, T.; Fan, W.; Yuan, W.; Wei, Y.-N.; Yu, B. Three-dimensional pore network characterization of loess and paleosol stratigraphy from South Jingyang Plateau, China. Environ. Earth Sci. 2019, 78, 333. [CrossRef]

32. Duan, Z.; Cheng, W.-C.; Peng, J.-B.; Wang, Q.-Y.; Chen, W. Investigation into the triggering mechanism of loess landslides in the south Jingyang platform, Shaanxi province. Bull. Eng. Geol. Environ. 2019, 78, 4919-4930. [CrossRef]

33. D4318-10; Standard Test Methods for Liquid Limit, Plastic Limit, and Plasticity Index of Soils. ASTM International: West Conshohocken, PA, USA, 2010.

34. D 854; Standard Test Methods for Specific Gravity of Soil Solids by Water Pycnometer. ASTM International: West Conshohocken, PA, USA, 2014.

35. D 2216; Standard Test Methods for Laboratory Determination of Water (Moisture) Content of Soil and Rock by Mass. ASTM International: West Conshohocken, PA, USA, 2010.

36. D 6836; Standard Test Methods for Determination of the Soil Water Characteristic Curve for Desorption Using a Hanging Column, Pressure Extractor, Chilled Mirror Hygrometer, and/or Centrifuge. ASTM International: West Conshohocken, PA, USA, 2002.

37. Sadeghi, H.; Hossen, S.B.; Chiu, A.C.; Cheng, Q.; Ng, C. Water retention curves of intact and re-compacted loess at different net stresses. Jpn. Geotech. Soc. Spéc. Publ. 2016, 2, 221-225. [CrossRef]

38. Guo, S.; Wu, J.; Dang, T.; Liu, W.; Li, Y.; Wei, W.; Syers, J.K. Impacts of fertilizer practices on environmental risk of nitrate in semiarid farmlands in the Loess Plateau of China. Plant Soil 2010, 330, 1-13. [CrossRef]

39. Xu, P.; Zhang, Q.; Qian, H.; Yang, F.; Zheng, L. Investigating the mechanism of pH effect on saturated permeability of remolded loess. Eng. Geol. 2021, 284, 105978. [CrossRef]

40. Hu, W.; Cheng, W.-C.; Wen, S.; Rahman, M. Effects of chemical contamination on microscale structural characteristics of intact loess and resultant macroscale mechanical properties. Catena 2021, 203, 105361. [CrossRef]

41. Nan, J.; Peng, J.; Zhu, F.; Ma, P.; Liu, R.; Leng, Y.; Meng, Z. Shear behavior and microstructural variation in loess from the Yan'an area, China. Eng. Geol. 2021, 280, 105964. [CrossRef]

42. Chen, X.; DU, S.; Zhang, D.; Li, B.; Ji, T. Triaxial creep properties of fiber reinforced expansive soil. J. Eng. Geol. $2017,25,80-87$.

43. Yang, S.-Q.; Hu, B. Creep and Long-Term Permeability of a Red Sandstone Subjected to Cyclic Loading After Thermal Treatments. Rock Mech. Rock Eng. 2018, 51, 2981-3004. [CrossRef]

44. Xie, X.; Qi, S.; Zhao, F.; Wang, D. Creep behavior and the microstructural evolution of loess-like soil from Xi'an area, China. Eng. Geol. 2018, 236, 43-59. [CrossRef]

45. Shukla, A.; Joshi, Y.M. Boltzmann superposition principle for a time-dependent soft material: Assessment under creep flow field. Rheol. Acta 2017, 56, 927-940. [CrossRef]

46. Wang, J.; Wang, X.; Zhan, H.; Qiu, H.; Hu, S. A new superlinear viscoplastic shear model for accelerated rheological deformation. Comput. Geotech. 2019, 114, 103132. [CrossRef]

47. Betten, J. Creep Mechanics; Springer Science \& Business Media: Berlin/Heidelberg, Germany, 2008.

48. Vinogradov, V.; Milton, G. The total creep of viscoelastic composites under hydrostatic or antiplane loading. J. Mech. Phys. Solids 2005, 53, 1248-1279. [CrossRef]

49. Al-Zubaydi, A.H.; Al-Atalla, M.A.; Al-Kiki, I.M. Long term strength and durability of clayey soil stabilized with lime. Eng. Technol. J. 2011, 29, 725-735.

50. Fatahi, B.; Le, T.M.; Le, M.Q.; Khabbaz, H. Soil creep effects on ground lateral deformation and pore water pressure under em-bankments. Geomech. Geoengin. 2013, 8, 107-124. [CrossRef]

51. Liu, L.; Xu, W. Experimental Researches on Long-Term Strength of Granite Gneiss. Adv. Mater. Sci. Eng. 2015, $2015,187616$. [CrossRef]

52. Kowalewski, Z.L. Assessment of the Multiaxial Creep Data Based on the Isochronous Creep Surface Concept. In IUTAM Symposium on Creep in Structures; Springer: Dordrecht, The Netherlands, 2001; pp. 401-410. [CrossRef]

53. Metri, V.; Briels, W. Brownian dynamics investigation of the Boltzmann superposition principle for orthogonal superposition rheology. J. Chem. Phys. 2019, 150, 014903. [CrossRef]

54. Cong, L.; Hu, X. Triaxial rheological property of sandstone under low confining pressure. Eng. Geol. 2017, 231, 45-55. [CrossRef]

55. Jury, W.A. Simulation of solute transport using a transfer function model. Water Resour. Res. 1982, 18, 363-368. [CrossRef]

56. Kong, R.; Gao, L.; Zhao, W.; Zhao, B. Multi-scale analysis of geotechnical and physicochemical changes in loess caused by nano-SiO2 pile migration. Front. Earth Sci. 2021, 9, 820. [CrossRef]

57. Yao, R.-J.; Yang, J.-S.; Zhang, T.-J.; Hong, L.-Z.; Wang, M.-W.; Yu, S.-P.; Wang, X.-P. Studies on soil water and salt balances and scenarios simulation using SaltMod in a coastal reclaimed farming area of eastern China. Agric. Water Manag. 2014, 131, 115-123. [CrossRef] 